\title{
Efficient Management of Municipal Enterprises
}

\author{
Dr. Davit Narmania \\ Prof. of Tbilisi State University, former mayor of Tbilisi City
}

\begin{abstract}
Municipal enterprises, as the local service providers, require a specific management approach. On the one hand, the municipal enterprises are organizations based on a certain commercial basis like LTD, Joint Stock Company and etc. and on the other hand, they have a different style of governance (e.g. municipal supervisory board). Additionally, the sources of budget formation are also different. They can have municipal funding as well as tariffs and commercial revenues. Planning, organizing, motivating and controlling management tools are used in municipal enterprises, like in commercial organizations. However, the implementation tools and functional subsystems are different (HR, communication, marketing, financial and operational management). Municipal enterprises are often required transparency, accountability and more corporate social responsibility than the private ones. This is caused by the fact that the municipal services are directly used by the citizens and in some cases, they are financed by civilians' taxes. Nowadays there are debates if public or private enterprises provide more valuable services (higher quality goods at a lower price) for citizens. Furthermore, if a private company is operating better, it creates possibility to privatize the public enterprise. However, in our work it won't be discussed. The main purpose of the paper is to determine the main postulates that will increase the efficiency of existing municipal enterprises. Accordingly, possible instruments are discussed in order to deliver public services, which have higher quality, are accessible and relatively inexpensive. In the paper theoretical and several practical examples of Georgia are discussed in order to improve municipal enterprise management efficiency.
\end{abstract}

Keywords: Municipal enterprise; Management; Efficiency; Service delivery.

\section{Introduction}

\section{Main Features of Municipal Enterprise}

Municipal enterprises, as the local service providers, require a specific management approach. On the one hand, the municipal enterprises are organizations based on a certain commercial basis like LTD, Joint Stock Company and etc. and on the other hand, they have a different style of governance (e.g. municipal supervisory board). Additionally, the sources of budget formation are also different. They can have municipal funding as well as tariffs and commercial revenues. Therefore, municipal enterprises are so called hybrid formations and their study is multidisciplinary (Leroy, 2009, p. 1).

Municipal enterprise is based on the local self-government to provide municipal services. Thus, they are autonomous organizations owned by municipalities, used to produce or deliver local public services outside the local bureaucracy (Voorn, Genugten, Thiel, 2017, p. 820). Such can be organizations related to passenger transportation, care of green plants, medical services, cleaning, recycling of remains and other similar ones. Therefore, the enterprise is a conditional conception, that may produce specific products (e.g. products derived from recycling of remains) or delivering municipal services (e.g. municipal dispensary). In most cases, municipal enterprises are the public significant service providers on the local level.

According to one common approach, the municipal enterprises will provide more efficient services than the private companies. However, there are opposers too. Additionally, there are frequently debates if public or private enterprises provide more valuable services (higher quality goods at a lower price) for citizens. Furthermore, if a private company is operating better, it creates possibility to privatize the public enterprise. There is a form of transfer managing right of public enterprise to a private company. In such case property remains municipal and the service is supplied by a private company. 
In addition, there is a public-private party form (PPP), when a specific public function is performed by a private company, based on a specially concluded contract.

There are several factors that are arguments for creating or maintaining public enterprises and they are united in four main groups (Leroy, 2009, p. 17):

1. Ideological conditions;

2. Acquisition or consolidation of political or economic power;

3. Historic heritage and Inertia;

4. Pragmatic responsibility on economic problems.

Unlike the ordinary and private companies, municipal enterprises have several characteristics (The Center for Audit Quality, 2011):

They are based by public law institutions (municipality);

Supervisory Board and Chief Executive Officer (CEO) is approved / appointed by the municipality;

Must deliver public service. Private service delivery by municipal enterprises is considered as a competition restriction on the market and is not feasible;

The municipal enterprise is accountable to the founder (municipality);

Depending on the public nature enterprise revenues and expenses may be fully or partially be public;

The public enterprise is required transparency and accountability, as well as corporate social responsibility;

Audit and control of the public enterprise is carried out by the municipality. However, by the invitation of the municipality the audit may conducted by an independent auditor based on a special methodology.

Public and private enterprises have the same responsibility of paying taxes. Otherwise discrimination and unequal competition will be on the market. Unacceptable that any municipal enterprise had an advantage in tax-finance mode. Furthermore, the European Directives also resist the different / discriminatory approaches.

\section{Management approaches in municipal enterprises}

Planning, organizing, motivating and controlling management tools are used in municipal enterprises, like in commercial organizations. However, the implementation tools and functional subsystems are different (HR, communication, marketing, financial and operational management).

Municipalities often participate in planning activities of municipal enterprises. It is important to have long-term strategic as well as short-term operational plans. However, decisions at the operational level are often received spontaneously, which is due to fast response to the needs of the local population. On the one hand it is advantageous compared to a private organization, but on the other hand it may be contradictory with the medium or long term plans. Therefore, municipal enterprises have to find a convenient way between strategic importance tasks and short-term needs when organizing the work.

Motivation in both municipal and private enterprises are very important, while it ensures better employee work performance. In both cases the same forms of motivation are used (promotion, cash reward, career advancement and etc.). Despite the public companies may be limited in order to use some of the available forms of encouragement. For example in most cases upper pay margin is established in the municipal enterprises and they do not have the possibility of giving more. In such case, there may be a staff outflow from public to a private companies which do not have such restrictions. The outflow of qualified personnel will be negatively reflected on the enterprises. However, this may not happen everywhere: in countries where labour unions are relatively powerful, such as in Spain and Portugal, unions have been known to demand higher salaries for the same jobs to accept the creation of municipal entreprises, to compensate for workers' reduced job security (Voorn, Genugten, Thiel, 2017, p. 825). 
A right organization of work and efficient results need a good leadership. The upper level heads in municipal enterprises are approved by the municipalities and afterwards these heads are taking decisions on medium and low level. Therefore, the municipalities should pay particular attention to the selection of high-level managers in the enterprises (such as CEO, CFO and others).

The control of municipal enterprises is mostly carried out by municipal controlling organizations. However, an independent auditor may be invited. It is important here to differentiate management control (managers' daily observation) and financial control (audit). Additionally, the municipal enterprise efficiency significantly depends on the efficient work controlling system. Finally, the main task of controlling is to introduce an efficient system of decision-making and analysis, which requires planning-organizing, accounting-reporting, monitoring and controlling the systems completely (Khomeriki, 2008, p. 183).

Municipal enterprises are often required transparency, accountability and more corporate social responsibility than the private ones. This is caused by the fact that the municipal services are directly used by the citizens and in some cases, they are financed by civilians' taxes. That is why municipal enterprises often publish their own financial indicators, audit acts, annual reports, various activities and achievements.

\section{Ways of improving management efficiency}

The main task of improving management efficiency in the municipal enterprises is to deliver lower price and high quality public services on time. However, this is not an exhaustive list. The forms of service delivery are different and depends on specificity of municipal enterprises.

In addition, efficient production should be ensured by the enterprise efficient management system. That is why a direct proportional connection is between them. Finally, in case of efficient functioning of municipal enterprises the local population is winning.

Profit-loss ratio, minimization of losses, external audit, social responsibility and other indicators and tools are used in order to assess the efficiency of municipal enterprises. Data Envelopment Analysis (DEA) is a comparatively complex analys form. It is a non-parameter method in operational research and economics and is based on 50 assessment indicators and is used to evaluate the production thresholds (IJET-IJENS, 2014, p. 43). In the end, the efficiency is expressed in the ratio of the weighted sum of outputs and weighted sum of inputs:

$$
\text { Efficiency }=\frac{\text { Weighted Sum of Outputs }}{\text { Weighted Sum of Inputs }}
$$

Management mostly depends on index of efficiency and effectiveness. The main task of managers is to achieve the objectives by using human, financial and industrial resources efficiently (Robbins, Coulter, 2014, pp. 7-8).

Based on the theoretical material and the existing practice, the following key indicators of efficiency are allocated:

Work/product quality delivery - e.g. high-quality asphalt cover in the settlement, underground communications and their maximal exploitation period. For this purpose, the municipalities should conduct efficient work control and based on the work carried out the municipal enterprises should compensate the payment to the company;

Maximum lower price service delivery - e.g. lower utility tariffs on cleaning, passenger transportation or lighting services. However, low tariffs do not always provide better quality. Therefore, it is important to identify service tariffs correctly. Municipal enterprises should remit expenses and leave at least the point of interest. Otherwise, the municipalitys will have to subsidize from the company's budget;

Timely delivery services - e.g. conducting vaccination in municipal clinics at a right time that is precisely defined for preventing certain diseases. For this purpose, polyclinic should be aware of the expected diseases from the health care facilities and have a sufficient supplies of vaccines;

Availability of services - e.g. allocate the household waste bin as close as possible near the settlement and make it empty as often as possible (transfer the waste to recycling plant). Additionally, it is important that the population does not bother the smell and the filling of rubbish. 
Besides the efficiency of enterprises, it is important to differentiate effectiveness. If efficiency is a specific measurable indicator, effectivness is more generalized. High quality, timely and affordable price delivery of goods and services that we have discussed above are within effective delivery. While delivering high quality goods or services to lower price is an indicator of efficiency.

In conclusion, we can say that in some sphere the existence of a municipal enterprises are necessary. But this is justified when in the municipal enterprises the efficient management system is implemented. This means creation more public products or services. Furthermore, we should ensure timely, better quality and low-cost delivery with limited resources. Efficient management in municipal enterprises implies efficient delivery of services and goods to the customers. This means, that local population of the municipality remains satisfied.

\section{References}

[1] Bart Voorn, Marieke L. van Genugten, Sandra van Thiel. (2017), The efficiency and effectiveness of municipally owned corporations: a systematic review, Local Government Studies, Vol: 43, No5.

[2] Khomeriki T. (2008), Basic Management, Tbilisi State University.

Leroy P.J. (2009), Public enterprise in less-developed countries, Cambridge university press.

[3] Robbins S.P., Coulter M., (2014), Management, Perason, Twelfth Edition.

[4] Efficiency Evaluation of the Municipal Management of Public Services of Water Supply, Sanitary Sewerage and Solid Waste (2014), International Journal of Engineering \& Technology IJET-IJENS, Vol:14 No01.

[5] In-Depth Guide to Public Company Auditing: The Financial Statement Audit (2011), The Center for Audit Quality, Washington DC.

[6] Tbilisi City Hall, www.tbilisi.gov.ge 